\begin{tabular}{|c|c|}
\hline 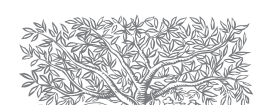 & Revista Española de \\
\hline $\begin{array}{l}\text { S.5. } \\
\text { ELSEVIER } \\
\text { DOYMA }\end{array}$ & $\begin{array}{c}\text { Nutrición Humana y Dietética } \\
\text { mmwelesevieres dietetetica }\end{array}$ \\
\hline
\end{tabular}

FE DE ERRORES

\title{
V Congreso de la Asociación Española de Dietistas-Nutricionistas. Investigación y práctica: claves en el futuro en dietética y nutrición
}

\section{FE DE ERRORES}

En el Volumen 15, Número 3, Julio-Septiembre 2011 de REvista Española de Nutrición Humana y Dietética, dedicado al "V congreso de la Asociación Española de Dietistas-Nutricionistas. Investigación y práctica: claves de futuro en dietética y nutrición", en el apartado de "Comunicaciones Científicas" se ha publicado por error la comunicación P-ORIG-051 "Efectos del consumo de PUFA n-3 en animales con síndrome metabólico", de los autores L. Lluís, M. Muñoz, N. Taltavull, V. Sánchez-Martos, M. Romeu, M. Giralt, M. Jové, À. Fortuño y R. Nogués. Dicha comunicación fue retirada por los autores debido a factores ajenos a la organización. 